\title{
Exchanges
}

In the Exchanges, we present conversations with scholars and practitioners of community engagement, responses to previously published material, and other reflections on various aspects of community-engaged scholarship meant to provoke further dialogue and discussion. We invite our readers to offer in this section their own thoughts and ideas on the meanings and understandings of engaged scholarship, as practiced in local or faraway communities, diverse cultural settings, and various disciplinary contexts. We especially welcome community-based scholars' views and opinions on their collaboration with university-based partners in particular and on engaged scholarship in general.

\section{Relationship, Accountability, Justice: A Conversation about Community-Engaged Research}

\section{Sarah Buhler, Sue Delanoy, Amanda Dodge, Chantelle Johnson, Jason Mercredi, Heather Peters and Stan Tu'Inukuafe}

In 2015, a coalition of six Saskatoon community organizations (the Elizabeth Fry Society of Saskatchewan, AIDS Saskatoon, STR8 UP 10,000 Little Steps to Healing, Inc., the Mennonite Central Committee, the Micah Mission, and Community Legal Assistance Services for Saskatoon Inner City [CLASSIC] $)^{1}$ and a university researcher (Sarah Buhler from the University of Saskatchewan College of Law) came together to address the issue of telephone access in Saskatchewan's provincial correctional centres. Together we established an informal research coalition that we called "Project Access." The issue of telephone access in provincial prisons had been identified by the six community organizations through their ongoing work with prisoners and former prisoners. Specific concerns included the exorbitant costs of the prison telephone system and unfair and uneven application of policies regarding telephone access. As we met to discuss the issue, it became clear to us that in order to advocate effectively for changes to the system, we needed to research the issue and to learn more about the ways the current telephone access policies were being implemented in provincial prisons.

The Project Access coalition collectively determined that we should apply for funding to undertake a literature review and qualitative study to learn more about

\footnotetext{
${ }^{1}$ See: http://www.elizabethfrysask.org/ ; http://www.aidssaskatoon.ca/ ; http://str8-up.ca/ ; https://mcccanada.ca/learn/ where/canada/saskatchewan; http://themicahmission.org/ ; http://www.classiclaw.ca/
} 
former prisoners' experiences of the prison telephone system. We were fortunate to receive funding through the Centre for Forensic Behavioural Sciences and Justice Studies at the University of Saskatchewan for our project, and were able to interview a total of 37 individuals who had been incarcerated in a provincial correctional centre in the previous two years. Our research led to a detailed report to the Ministry of Justice, public and community presentations, and a public report and infographic. ${ }^{2}$ It also led to a meeting of coalition members with the provincial Minister of Justice, who announced changes to the inmate telephone system that responded to several of the concerns we raised in our report shortly thereafter.

Throughout the more than two years that the Project Access coalition worked on the research project, we met monthly. Following the completion of our project, coalition members determined that we wanted to continue to work together on research projects related to issues and concerns in the community. We decided also to meet to discuss and critically reflect on the process of working together in this research project. The following is the edited transcript of our discussion. In order of their appearance in the conversation, the participants were as follows: Sarah Buhler (Associate Professor, University of Saskatchewan College of Law); Jason Mercredi (Executive Director, AIDS Saskatoon); Heather Peters (Restorative Justice Coordinator, Mennonite Central Committee Saskatchewan); Stan Tu'Inukuafe (Outreach worker, STR8 UP); Amanda Dodge (Supervising Lawyer, CLASSIC); Sue Delanoy (Executive Director, Elizabeth Fry Society of Saskatchewan); Chantelle Johnson (Executive Director, CLASSIC).

Sarah: Let's start with talking about how everyone originally got involved in this project.

Jason: Amanda from CLASSIC came to our drop-in centre to just chat about issues we have in the community and this issue of telephone access for prisoners was one I identified to her. I wanted to be involved because it was an issue that we at our organization had been banging our heads against the wall about for about two years.

Heather: Yes, Amanda and I originally had a discussion about some different root problems that we see in our correctional centres and our community, and then she contacted me a few months later saying that this issue of telephone access in prisons was one that we wanted to focus on. So we came to see what it was going to evolve into.

Stan: That is what happened with us at STR8 UP too.

Amanda: When CLASSIC's Systemic Initiatives Program was getting developed we consulted

\footnotetext{
${ }^{2}$ These documents will be available soon on the website of the Centre for Forensic Behavioural Sciences and Justice Studies at the University of Saskatchewan: http://www.usask.ca/cfbsjs/
} 
community agencies and this systemic issue came up repeatedly. It was great to have not only the community agencies speaking into it but then wanting to participate and come to the table and work more collaboratively together.

Sarah: From my perspective my involvement also emerged primarily through my ongoing relationship with CLASSIC. It is interesting to me to point out that although some of the coalition members had not worked together before, there was a framework of pre-existing relationship for some of the community organizations and people involved.

Amanda: I think there is an interesting contrast between the existing relationships among community organizations and the new ones. With CLASSIC's systemic work, we were looking at agencies that support prisoners; some of them we had relationships with and some of them we didn't. So it was a great opportunity to do some outreach and build some new relationships through the work.

Sue: I got involved after speaking individually with everyone about this situation, and talking with CLASSIC about the opportunity to delve deeper into some of the issues all of the groups have experienced within our organizations regarding incarceration policies and practices.

Sarah: So can people share why they got involved with this project and this issue of telephone access in provincial prisons?

Jason: AIDS Saskatoon works with people who are HIV positive in the province. Our concern was that HIV rates are very high in the provincial prison system and it was important for us to have access to people we are trying to reach out to. Getting involved in a research project like this and trying to influence change to the system and increase telephone access made sense.

Sue: Our, the Elizabeth Fry Society, works with women and girls who are facing the criminal justice system or directly involved with incarceration. We hear directly from the women about the situations while incarcerated that halt their progress while inside, and stymie their abilities for a successful reintegration back into their communities. We also wanted to be involved with a project that could influence change and after much discussions regarding some of the challenges in the various institutions. Telephone access was one of the main frustrations with many of the women. Also the ability to give voice to the women was extremely important to us!

Heather: Our organization, the Mennonite Central Committee, does not do direct programming within prisons but we do support education and advocacy on justice issues. Being part of this research project was really important in that it supported community 
organizations and was a different kind of advocacy work. So it was really important for us to be here.

Stan: From our perspective, we not only got involved in this project because STR8 UP members all have experienced incarceration, but we also got involved because from an organizational perspective we believe that it is important for the individuals who access STR8 UP be given a space where they can have their voices heard.

Amanda: CLASSIC is committed to working collaboratively in our systemic advocacy work. I think being involved in a partnership like this enhances the credibility of the work we do in at least two ways. One, it taps into the expertise of the community agencies that come around the table. Then secondly, it enhances our credibility with the decision makers that we are appealing to for change. Working together like this means that no one is standing alone or even in a group of two; here, there are six of us standing together saying this telephone system in the prisons needed to change. It increases the credibility of the work considerably.

Chantelle: Our legal clinic represents people in provincial correctional centres. We noticed that this issue of telephone access was affecting them and was important to address.

Sarah: For me, I had pre-existing relationships with most of the people and organizations that are involved in this project. As a university researcher, my priority and my goal has been to link the work that I do to projects that will benefit the community. It is really exciting when something like this comes along. The research topic and the desire to do the project arose directly from the community organizations, and I would definitely not have been able to identify prison telephone access as a key issue sitting alone in my office at the university.

Amanda: It is a good lesson in how accessible that dialogue can be. I don't think it was a hardship for us to have those initial conversations. I think it was half an hour, or an hour, in each other's offices just chatting about "what are the systemic issues the folks you are working with facing?", that led us to identify this as a topic of common concern.

Sue: Ditto! This experience of all working together was very positive to delve deeper into an issue that impacted so deeply the people that we serve. Also unpacking the actual correctional telephone policies was extremely interesting to understand the workings of the governmental policies, and then to put voice to the ramifications of these policies.

Jason: I have had many conversations with researchers or people who want to do communitybased research. And usually you never hear from them again and so I wasn't necessarily expecting it to lead to anything at first. 
Sarah: Interesting, and why do you think that is, that you usually don't hear back from researchers?

Jason: I think navigating this many relationships is not easy. The coordination of this kind of research takes time and effort. And also there can be lots of egos involved and so sometimes it's just, people like the idea of community based research but once they start doing it they get cold feet or realize it's too time consuming.

Sue: I agree with Jason, it was lovely to be with others who had a comprehensive understanding of the work that we all do, the simplicity of it and the complications involved. Also the other organizations are extremely knowledgeable, easy to work with, and very generous in their abilities to get along with each other.

Stan: And I think sometimes university researchers think they want to do research with the community but they actually have a preconceived idea of what they want to research. And when a community identifies a different need, then the university researcher might say: "oh, that's not really what I was thinking."

Jason: I have had that experience where I am involved in a research project but the researchers clearly have an intended purpose and even though the community partners identify a different concern, the university researchers keep trying to shift the focus back to what they would like the focus to be.

Stan: Yeah, because a lot of times I think the university researcher already has written up how their funding is structured so they have to fit what they are doing in that box instead of coming and discussing the research with the community first. Our process with this project was different because it evolved over time, right?

Amanda: For the community agencies around the table, did you feel like you could steer the ship in terms of the direction of the research?

Jason: It felt very relational.

Many Voices: Yes. Yeah.

Sue: This project is very much a compilation of many voices and no one seemed to overpower another organization. It was definitely not heavy handed academic wise, or community wise. It felt like a true collaboration, and one that I hope to pursue on other topics. I learned a lot from my peers and respect each and every one of them immensely.

Stan: But I think, from my perspective, it is only because of the relationships we already had, 
right? People around our table felt comfortable to give their opinions and be involved.

Sarah: I feel like relationship is a theme that runs through any of this kind of work. It is front and centre.

Stan: And for me, to be honest, when I come to a group, I see who is at the table, and if I feel they are "doers", I am more engaged, because I know things will be followed up, as compared to just coming and talking. Because I hate coming to meetings to just have a meeting, I don't have time for that. For me, I am really aware of who is at the table. I don't know if others do that but it's something I do.

Heather: It is also realizing that relationships take time too. And that is why this project took time a while.

Sue: The relationships were there before the project, but were deepened and widened with this project.

Sarah: What did you understand the purpose or goal of the collaboration to be, when it first started? What did you feel you could bring to the table and to this research project?

Heather: I understood the purpose to be to do a research project together on an important issue identified by the community.

Sue: I did too, but also liked that this was a project whereby we could directly involve the women who we work with.

Amanda: For CLASSIC's perspective, we were wanting to see recommendations for legal and policy change. We thought that we could bring a legal lens, as well as legal research and support to the project.

Jason: We work in partnership, that's how we do almost everything we do. I have worked with a couple bigger coalitions so I thought I could bring that experience, especially the bigger advocacy piece, to the table.

Chantelle: I feel like all the partners at this table brought really unique perspectives and we learned from each other throughout the course of the project.

Sarah: And there was a strength in numbers too, I think. A feeling of legitimacy. Most of the organizations that do front line work within prisons and with former prisoners in Saskatoon were at the table. I think that really brought us solidarity into the project. So let's move on to the next question: How important was it to have the university research 
capacity involved? What do you see as the main benefits and drawbacks of the University research involvement in community based research projects?

Jason: The benefits are definitely the increased capacity that this brings. No community based organization I know of has a researcher on staff. Another benefit was the ability to access funding for the project. I don't think any of us within community organizations would have had the time. An academic background is good because while I think we can translate results to the community, an academic can help translate results to policy makers and other academics. For this project, if we didn't have that research capacity, we would be in the exact same place now that we were in three years ago. We were actually able to show that we are basing our policy recommendations in fact and with the empirical evidence to support it. The limitations that we faced in our project had to do with the issue of advocacy. Some of our organizations, as charitable organizations, have limits in terms of how we can advocate on issues in order to maintain our charitable status. University researchers have academic freedom and don't have those limits. So the issue was that it was important that any publications that came out of the research didn't cross the line in terms of advocacy.

Sue: Well said, I could not agree more!

Chantelle: There can be that tension - the university researcher needs to publish and the community organizations want to ensure we are in line with our obligations not to cross the line in terms of advocacy, so I think if that the university is really interested in community based research, this is one of the areas to acknowledge.

Jason: A lot of times academic research doesn't really result in changes policy wise or other because it sometimes feels like they just want to toot their own horn instead of being very strategic in how they present their message.

Sarah: I think that speaks to the dominant ethos of academic research: there can be this idea that we as academic researchers should try to be neutral, to just provide information or get the evidence. Of course, critical perspectives show that all knowledge is political in some way and how you choose what to research shows values and shows ideology and all that kind of thing. But not all researchers take a strategic perspective or see themselves as advocates, I think most don't, right?

Chantelle: Whereas that is super important if you are doing community engaged research because if you are gathering all the research and not thinking about the consequences you are probably going to run out of community to do community engaged research with!

Stan: For STR8 UP, we are relatively new as an organization. For us, getting involved in a 
project like this in conjunction with the university and the other organizations involved makes us more credible in a sense.

Amanda: I thought that one of the real benefits the partnership with the university was the ethics approval process for the interviews that we did. To have that protection from the ethics approval process through the university, and to be able to publish the results and share them because there was such a high standard applied to that. I also want to echo the previous comments about how the partnership gave voice to the project in a way that community based agencies might not be able to express on their own. The university partnership also gave us a forum to present on our research. For example, when we were involved in presenting at a Human Rights conference at the College of Law; that would not have been possible without the university connection.

Sue: This partnership and initiative gave us legitimacy to prove something that we already knew or felt intuitively, it offered us the opportunity to prove through research what we thought, and gave our advocacy more legitimacy.

Sarah: So it sounds like overall, I am hearing a net positive impact. But with sort of some hurdles that we had to deal with along the way, competing interests and issues that arose along the way that I think we really hashed through.

Chantelle: And I think that it is important to reflect back to the discussion we had on the other questions. The community-university relationship was successful because we already knew you Sarah, and we had a relationship with you. I am not sure how well we would have done with someone from the university that we don't know who just parachuted in.

Sue: I think it would have been more difficult with someone who we had not known, but the organizations and the individuals are all real doers, so this was a win -win all around.

Jason: Especially when you are talking about what happens with the results of the research. We get approached for research all the time and sometimes we say no because sometimes I get a bad sense that the person is going to take whatever they want and run with it. But, because we have that relationship and there is a level of trust that you are not going to screw us in the end if we identify something of concern, this worked well.

Chantelle: Whereas that might happen with somebody who isn't as entrenched in the community who might just prefer to get published and not care about all the rest of our interests and needs.

Stan: There was a lot of trust between all of the members of the group. This really was based on the fact that we had a relationship among us. 
Sarah: Does anyone want to speak to how important it was to have students involved in our project? We had, as you know, a series of university student research assistants throughout the time on our project.

Amanda: They were so fantastic to have - students who were able to go and do the interviews, many of them, and help with some of the research we needed. Students did legal research, policy research, sociological research, and even economic research. It was just fantastic. In addition to that, what a great learning experience for students to be sitting around this table, to see collaborative systemic advocacy at work, across different disciplines and with the different perspectives.

Sarah: How did the collaborative nature of the project strengthen it, and did it bring challenges? I know we have touched on these questions already to some extent.

Chantelle: I agree with what Stan said earlier about the way that working collaboratively increases the credibility of the work.

Heather: And a challenge is the length of time that it takes to finish anything when you are working as a group!

Jason: I think too there was a number of times we would disagree on stuff because we could talk it through, versus if there was just one person they could potentially dominate the conversation. When we were talking about messaging and that got heated, we would disagree on it but come to some kind of resolution. That is a big strength in this type of research.

Amanda: There seems to be a lot of equity around the table. Everyone's voice was valued equally, that is a real strength. And also I always looked forward to the meetings because I liked the people around the table. We enjoy each other's company in addition to working well together. We laugh together and I think those things matter in terms of "am I going to go to this meeting or not, am I going to make time for this?”. Whether you are enjoying the work and the people you are working with can determine engagement.

Sue: Students always bring a good perspective to any project.

Sarah: I think what was really interesting and worked really well with this project was the actual design of the research. It actually happened collaboratively right from the start. First of all, the idea for the project came about from the community partners. We also worked together to figure out the research questions and protocols. I feel like the whole process was collaborative. And then even the interpretation and analysis of the data, community partners worked on that together. 
Amanda: A difference maker, I think, is that CLASSIC had set aside resources for systemic advocacy. Oftentimes this work is done "off the sides of people's desks" as it were. Because CLASSIC dedicated resources, we had a staff member who could work to coordinate the meetings and supervise the students, and a site to host meetings and house the material. That kept the collaboration supported and moving forward.

Sarah: So what are the key elements of successful community based research and advocacy in your view?

Amanda: I would underscore the importance of data as a key element of our project. The interviews with former prisoners yielded such credible data because it was from those affected. It wasn't just that we were blustering on a position but that our position was strongly supported through the voices of people affected and the legal and sociological research.

Heather: I agree.

Sue: Me too!

Chantelle: Maybe the flexibility and nimbleness amongst the collaborators to be able to work with one another and understand the barriers to what we faced a year into the project. And again, that comes because of relationship.

Amanda: I'll add to this the importance of the commitment of people around the table. I mean, this was a three-year long project and everyone kept coming to meetings. It is pretty amazing.

Sarah: Does anyone have reflections on power dynamics within the group?

Jason: I thought it was pretty good.

Sue: I enjoyed being part of this group. I felt like everyone learned from each other and it felt equitable.

Amanda: It felt equitable and I think that is commendable thinking about the diversity of people around the table, like gender and organizations. No one was asserting that their personal or organizational capacity was more important or needed to dominate what we were doing.

Sarah: Are there any reflections on the ethical issues that arise generally in community based research and advocacy and how they should be addressed? Were there any ethical issues 
in this project that arose? We spoke earlier about the importance of having the research ethics board approve the protocol.

Amanda: One thing I have heard a lot from the community is that people keep researching us but aren't bringing a benefit into our lives as a result of this research. Our cultural advisor and elder Maria Campbell has said you always need to honour the principle of reciprocity. There needs to be a tangible benefit that the community experiences as a result of the research. Now, how do you ensure that happens from the outset of the project when you don't know if you are going to be successful? I think we have been fortunate in that we have had some success with our project and we can say we think that there is now a (small) benefit to people incarcerated or in conflict with the law as a result of our project. So I like that our project was able to honor the principle of reciprocity in terms of the systems change that started as a result of the advocacy.

Heather: I think we are fortunate that we have something tangible that we can point to and that there has actually been change because I think that rarely happens.

Chantelle: Often systemic changes are a trickle down result. You don't see results for years. It does not say that the work is not important but how does it translate to the people connected to it? We could strategize about this and learn from the community.

Sarah: What are the risks, if anything, to the community of community based research? And potentially of this project?

Jason: Funding backlash. These are the types of things, if the powers that be are not happy with the research that community groups are doing and what they do with it, they might lose funding.

Sue: Exposing publically what we already might know, then working to change public perceptions, and also highlighting something to the government that they might change their minds on negatively is always a risk.

Heather: Also, the people that we engage with, they make themselves vulnerable in the interviews and as we collect data and if nothing comes of it, why would they do that again, right?

Stan: And maybe as community organizations, if we have misunderstood the goals and objectives, it could strain relationships amongst the partners.

Sarah: What do university researchers need to know in order to work effectively with community engaged research? 
Jason: Time commitment, you have to be willing to put in the time. And so, don't come knocking if you are not willing to put in the time.

Amanda: Build relationships, make yourself known. Don't swoop in from the campus and just swoop back.

Sue: Understand the community you are seeking to work with!

Chantelle: And be careful to learn what the priorities are of the community partner and be aware that this might be a consideration in terms of how the research is presented.

Sarah: So be prepared to be accountable to the community.

Amanda: And you have had to make compromises because of that accountability.

Jason: I have been involved in a number of research projects where I felt like I was resume padding for someone and I didn't appreciate that. So if you are looking for some sort of thing to put on your cv, then community based research is not for you.

Sarah: So what are your hopes in the future in terms of this group?

Amanda: I think we know we have a good thing going and we want to take on other issues in the future. We are talking about our next project, and need to make some decisions around that. It is exciting to think about future impact.

Heather: My hope is that we can continue our work as a coalition to research injustice and that it comes from our work and where we see the needs.

Sue: I hope we can continue to work together on other initiatives and build solidarity!

Stan: Our hope too is that we would continue moving forward together.

Chantelle: I think that a whole bunch more comes from this type of collaboration than the actual project results themselves. Over three years we have gotten to know each other quite well. The networking and mutual support beyond this project is invaluable - if something comes up, you can contact one another. I wouldn't feel uncomfortable contacting Stan or Heather now with an issue beyond this group's focus. So I think the benefits for the community are a lot broader than just the research results. 


\section{About the Participants}

Sarah Buhler (corresponding author) is an Associate Professor at the University of Saskatchewan College of Law. She is involved in community-engaged research that considers the impacts of the legal system on marginalized communities, and works closely with CLASSIC (Community Legal Assistance Services for Saskatoon Inner City). Email: sarah.buhler@usask.ca

Sue Delanoy is the Executive Director of the Elizabeth Fry Society of Saskatchewan. Prior to her involvement with the Elizabeth Fry Society she was the National Executive Director in Ottawa Canada, for the CCAAC (Child Care Advocacy Association of Canada). She spent 10 years as Children and Youth Advocate for Communities for Children in Saskatoon and 10 years before that as the Executive Director of the provincial Saskatchewan Early Childhood Association.

Amanda Dodge is the Program Director at the Mennonite Central Committee of Saskatchewan (MCC). Prior to her work with MCC, Amanda was a supervising lawyer at CLASSIC (Community Legal Assistance Services for Saskatoon Inner City) and director of CLASSIC's Systemic Initiatives program.

Chantelle Johnson has been the Executive Director of CLASSIC (Community Legal Assistance Services for Saskatoon Inner City) since 2012. She has B.A. and LL.B. degrees from the University of Saskatchewan. She has previously worked with the Saskatchewan Human Rights Commission, with the Child Sexual Exploitation Unit in Edmonton, as Crown Counsel in British Columbia, and as an intern at the Indigenous Law and Justice Branch in Australia.

Jason Mercredi is the Executive Director at AIDS Saskatoon, he has been with the agency for the past five years and has over a decade of non-profit experience. He is a Board member for the Canadian AIDS Society, SUM Theatre, Saskatoon Housing Authority, and the 33rd Street Business Improvement District. He is an advocate for Harm Reduction and health equity. He is of Metis, Dene and Scottish ancestry and hails from Treaty 6 and the homeland of the Metis.

Heather Peters is the Peacebuilding Coordinator for Mennonite Central Committee Saskatchewan. In this role she connects with communities in Saskatchewan who are interested in trauma awareness, restorative justice and reconciliation.

Stan Tu'Inukuafe has been supporting those involved in the criminal justice system for the past ten plus years. He is married and the father of four beautiful girls. Stan currently works as a school social worker at Oskāyak high school in Saskatoon, Saskatchewan. 